\title{
An observational study on extraperitoneal caesarean section in present era
}

\author{
Sudhanshu Sekhara Nanda*, Subhalaxmi Dash, Anju Huria, Reeti Mehra
}

Department of Obstetrics \& Gynaecology, Govt. Medical College \& Hospital, Chandigarh, India

Received: 6 August 2014

Accepted: 19 August 2014

\author{
*Correspondence: \\ Dr. Sudhanshu Sekhara Nanda, \\ E-mail: sudhansu81@gmail.com
}

(C) 2014 Nanda SS et al. This is an open-access article distributed under the terms of the Creative Commons Attribution Non-Commercial License, which permits unrestricted non-commercial use, distribution, and reproduction in any medium, provided the original work is properly cited.

\begin{abstract}
Background: This study was designed to find out the maternal and perinatal outcome in cases of extraperitoneal caesarean section. Total 100 women undergoing extraperitoneal cesarean section were included in the study.

Methods: A detailed history taking, examination done and intra and post-operative parameters as per protocols were noted.

Results: Success rate of extra peritoneal CS was $79.63 \%$, Time taken from incision to delivery was $\leq 5$ minutes in $60 \%$ cases, time taken from incision to closure was between $31-45 \mathrm{~min}$ in $67 \%$ cases, blood loss $\leq 500 \mathrm{ml}$ in $58 \%$ cases, return of bowel function between 5-8 hours in 52\%, mobilization within 24 hours in 52\%, neonatal one minute APGAR score $\geq 7$ in $90.91 \%$.

Conclusions: Extraperitoneal cesarean section can be applied as a surgical form of infection prophylaxis. Since it possesses a rational basis for the avoidance of serious post-operative pelvic infectious complications, this operation deserves reconsideration in the modern era.
\end{abstract}

Keywords: Extraperitoneal, Caesarean section, Transperitoneal

\section{INTRODUCTION}

Maternal mortality due to caesarean section has been reduced drastically but the morbidity in terms of pain, infection and adhesions still persists. This morbidity is mainly due to the soiling of the peritoneal cavity especially by infected amniotic fluid from the uterus, blood and due to bowel handling.

When the peritoneal cavity is opened as in the transperitoneal approach, there is entry of organisms into the peritoneum not only from skin and fascia but also from amniotic fluid especially when infected. Moreover, peritoneal cavity and intestines are subjected to dryness, and, chemical and physical injury by packs and tetra. ${ }^{1}$ So it is associated with wound sepsis, paralytic ileus, peritonitis and septicemia, especially in cases of prelabour rupture of membrane and prolonged labour resulting in prolonged hospital stay. ${ }^{1,2}$
To reduce the morbidity and higher mortality of classical trans-peritoneal caesarean section in the pre-antibiotic era, the extraperitoneal approach was devised. It was first performed by Ferdinand Ritgen (1787-1867) of Gissen in 1821. ${ }^{3}$ The procedure was further modified by Latzko, Waters and Norton. This extraperitoneal approach reduced the mortality and morbidity to a significant extent.

\section{METHODS}

This observational study was conducted in the dept. of obstetrics \& gynaecology, govt. medical college \& hospital, Chandigarh, October 2011 to August 2012.

\section{Inclusion criteria}

All cases of extraperitoneal caesarean section - elective and emergency 


\section{Exclusion criteria}

Previous abdominal surgeries

Prior surgeries on bladder

Placenta praevia

Carcinoma cervix

Women requiring caesarean section with tubal sterilisation

\section{Operative technique}

The patients were given spinal anesthesia or general anesthesia as per requirement. Bladder catheterized. Transverse supra-pubic or longitudinal skin incision given. The rectus sheath was incised transversally and rectus muscles are separated apart. After separation of the recti, transversalis fascia was separated. This will expose the bladder covering the lower uterine segment. The peritoneal attachment to the dome of the bladder was first isolated by bilateral paravesical dissection that was followed by blunt dissection to separate the peritoneal fold which was pushed upward as far as possible to expose the lower uterine segment. The uterus was incised transversely and the incision was extended giving good space to deliver the baby. The placenta and membranes are delivered. The uterus was sutured with number one polyglactin 910 in single layer. Haemostasis checked and achieved. Surface of the bladder examined for bladder injury. Fundus of uterus palpated to look for atonicity. After confirming the mop count and the instrument count, rectus muscles are approximated and rectus sheath closed with polyglactine number O. Skin closure done.

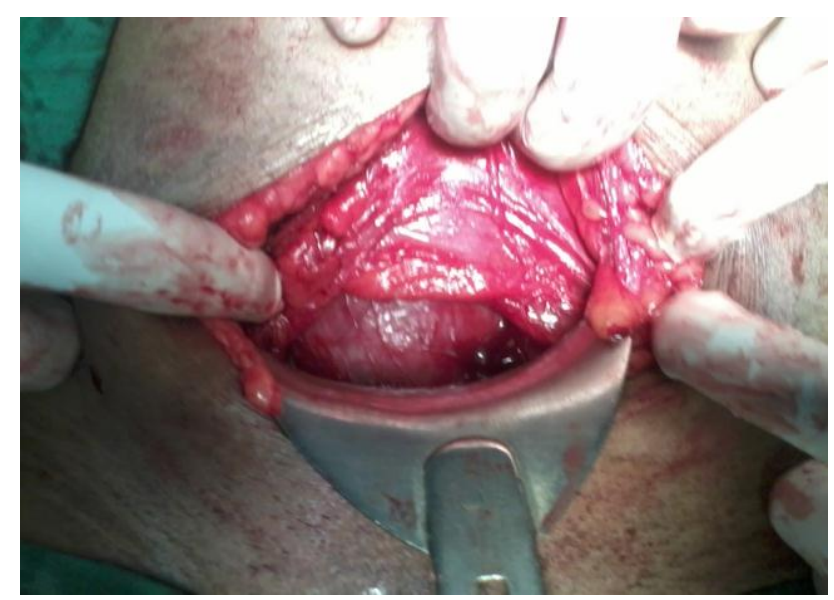

Figure 1: Lower uterine segment with intact fold of peritoneum.

Pre-operative antibiotic (Inj. cefaperazone + sulbactum) given to all patients before starting the procedure. During the post-operative period, patient's pulse, blood pressure, temperature were recorded daily. The patients were allowed oral diet after appearance of bowel sounds. Patients were encouraged to ambulate early. Routine injectable antibiotics and analgesics were given for 48 hours. Catheter removal was done routinely after 24 hours, except in cases of obstructed labor.

The post-operative complications like pyrexia, pain, abdominal distention, wound infection, etc. were taken into consideration and details reported. Post-operative pain was assessed using the visual analogue scale of 0 to 10 where ' 0 ' represents 'no pain' and ' 10 ' represents 'worst pain ever experienced'. Patients were discharged on third or fourth post-operative day if convalescence was uneventful.

\section{RESULTS}

In the present study of 100 cases of extraperitoneal cesarean section, meticulous analysis was done considering a wide range of parameters.

The maximum number of women belonged to the age group 21-30 years (71\%). Most of the women in our study were primigravida (90\%), $7 \%$ were second gravida and $3 \%$ third gravida. $88 \%$ of the women were term at delivery, $8 \%$ were preterm and $4 \%$ were post term. $93 \%$ of cases had a cephalic presentation, followed by breech $(5 \%)$ and transverse lie $(2 \%)$. Majority of patients had ruptured membranes at admission $(72 \%)$.

The most common indication for cesarean section was fetal distress (36\%), followed by CPD (25\%), oligohydramnios $(16 \%)$, fetal growth restriction $(9 \%)$, breech presentation $(5 \%)$, transverse lie $(2 \%)$, post term (2\%) and DTA (2\%). $3 \%$ of cases constituted other causes.

Of the 126 cases in which extraperitoneal cesarean section was tried, procedure was successful in 112 cases $(88.88 \%)$. Inadvertent entry into the peritoneum occurred in $11.12 \%$ of the cases (Table-1).

Table 1: Success rate of extraperitoneal CS.

\begin{tabular}{|lll|}
\multicolumn{1}{|l}{} & $\begin{array}{l}\text { No. of } \\
\text { cases }\end{array}$ & Percentage \\
\hline Cases tried & 126 & $100 \%$ \\
\hline Success & 112 & $88.88 \%$ \\
\hline $\begin{array}{l}\text { Inadvertent entry into } \\
\text { the peritoneum }\end{array}$ & 14 & $11.12 \%$ \\
\hline
\end{tabular}

The time taken from skin incision to baby delivery was $\leq 5$ minutes in $60 \%$ of the cases. In $8 \%$ of the cases, the incision-delivery interval was $>9$ minutes (Table 2). The duration of the surgery from skin incision to closure was between $31-45$ minutes in $67 \%$ of the women. The procedure took $>60$ minutes in $4 \%$ of cases (Table 3 ).

The total blood loss during the procedure was $\leq 500 \mathrm{ml}$ in $58 \%$ of the cases. Blood loss $>1000 \mathrm{ml}$ was present in $2 \%$ of the cases. 
Table 2: Time taken - incision to delivery.

\begin{tabular}{|lll|}
$\begin{array}{lll}\text { Incision-delivery } \\
\text { interval (minutes) }\end{array}$ & $\begin{array}{l}\text { No. of } \\
\text { cases }\end{array}$ & Percentage \\
\hline$\leq 5$ & 60 & $60 \%$ \\
\hline $5-9$ & 32 & $32 \%$ \\
\hline$>9$ & 8 & $8 \%$ \\
\hline
\end{tabular}

Table 3: Time taken - incision to closure.

\begin{tabular}{|lll|}
\hline $\begin{array}{l}\text { Incision-closure } \\
\text { interval (minutes) }\end{array}$ & $\begin{array}{l}\text { No. of } \\
\text { cases }\end{array}$ & Percentage \\
\hline$\leq 30$ & 20 & $20 \%$ \\
\hline $31-45$ & 67 & $67 \%$ \\
\hline $46-60$ & 9 & $9 \%$ \\
\hline$>60$ & 4 & $4 \%$ \\
\hline
\end{tabular}

Intra operative complications observed during our study included extension of uterine angle in one case and postpartum hemorrhage (atonic) in one case. No cases of bladder injuries occurred in our study. Maximum number of patients in our study $(84 \%)$ had pain scores between 0 5 . In $14 \%$ of the patients, pain scores were $6-7$, and, in $2 \%$ of patients score was $>8$ (Table 4 ). $83 \%$ of the women did not require any additional analgesics.

Table 4: Post-operative pain.

\begin{tabular}{|lll|}
$\begin{array}{l}\text { Pain } \\
\text { scores }\end{array}$ & $\begin{array}{l}\text { No. of } \\
\text { patients }\end{array}$ & Percentage \\
\hline $0-5$ & 84 & $84 \%$ \\
\hline $6-7$ & 14 & $14 \%$ \\
\hline$>8$ & 2 & $2 \%$ \\
\hline
\end{tabular}

Return of bowel sounds was present between 5-8 hours in $52 \%$ of the women. In $42 \%$ of the women, bowel sounds appeared at 4 hours (Table 5). Mobilization of the patient occurred within 24 hours in $52 \%$ of the patients, and, between $24-48$ hours in $42 \%$ of the patients (Table 6 ).

Table 5: Appearance of bowel sounds.

\begin{tabular}{|lll|}
\hline $\begin{array}{l}\text { A ppearance of bowel } \\
\text { sounds (hours) }\end{array}$ & $\begin{array}{l}\text { No. of } \\
\text { cases }\end{array}$ & Percentage \\
\hline 4 & 42 & $42 \%$ \\
\hline $5-8$ & 52 & $52 \%$ \\
\hline $9-12$ & 6 & $6 \%$ \\
\hline$>12$ & - & - \\
\hline
\end{tabular}

Table 6: Mobilization of patient.

\begin{tabular}{|lll|}
\hline $\begin{array}{l}\text { Mobilization of } \\
\text { patient (hours) }\end{array}$ & $\begin{array}{l}\text { No. of } \\
\text { cases }\end{array}$ & Percentage \\
\hline$\leq 24$ & 52 & $52 \%$ \\
\hline $24-48$ & 42 & $42 \%$ \\
\hline $48-72$ & 6 & $6 \%$ \\
\hline$>72$ & - & - \\
\hline
\end{tabular}

Post operatively, pyrexia was present in $4 \%$ cases, urinary tract infection in $4 \%$ cases and abdominal distension in $1 \%$ cases. No cases of wound infection, wound gaping, burst abdomen, sub-acute intestinal obstruction, sub-involution, pelvic abscess, peritonitis, venous thromboembolism or genitor-urinary fistula were present in our study.

Duration of hospital stay was $\leq 4$ days in $86 \%$ of cases. $4 \%$ of cases had prolonged stay in the hospital $>8$ days.

$57 \%$ of the babies born by extraperitoneal cesarean section in our study had birth weight between $2.6-3.5 \mathrm{~kg}$. $33 \%$ cases had birth weight $\leq 2.5 \mathrm{~kg}$ and in $10 \%$ cases, babies weighed $>3.5 \mathrm{~kg}$. The neonatal APGAR score was $\geq 7$ in $90.91 \%$ cases. No cases of birth injuries occurred in our study.

\section{DISCUSSION}

The complications like wound sepsis, paralytic ileus, peritonitis, septicemic shock and appreciable risk of death, occur in patients whose caesarean sections are to be performed in the presence of intra-uterine sepsis and after prolonged labour.

Some of these serious complications are preventable by better antecedent asepsis and appropriate antibiotics. Yet there remains a substantial hard core of doomed cases whose serious postoperative complications we are powerless to avert, and whose fate appears to lie in the lap of Fortune.

This stimulated attempts to consider resurrecting extraperitoneal caesarean section from obstetric history, in the hope of reducing what appeared to be insuperable risks of sepsis associated with caesarean section.

In addition to the decreased risk of infectious complications in comparison to the conventional transperitoneal caesarean section, the women undergoing extraperitoneal cesarean section can be advocated fluids and feeding earlier in the post-operative period, and also ambulate early thereby reducing hospital stay. If proper precautions are taken, complications like injury to the bladder and blood vessels can be averted. In the event of difficulty the procedure can be immediately converted to a trans-peritoneal procedure. In developing countries like ours where obstetric sepsis is still a major cause of morbidity and mortality, any procedure intended to prevent peritoneal contamination deserves consideration. Decreased infection rate, early mobilization and return of bowel function may weigh over the increased time taken for the procedure and technical difficulty.

Funding: The study was self-funded

Conflict of interest: None declared

Ethical approval: The study was approved by the institutional ethics committee 


\section{REFERENCES}

1. E. W. Cartwright. Extraperitonal caesarean section: Physick-Sellheim principle. West J Surg. 1949;57:509.

2. Derk Crichton. A simple technique of extraperitoneal caesarean section. S Afr Med J. 1973;47:2011.
3. Marshall CM. Extraperitoneal approach. In: Marshall CM, eds. Caesarean Section Lower Segment Operation. 1st ed. Bristol: John Wright; 1939.

DOI: $10.5455 / 2320-1770 . i j r \operatorname{cog} 20140976$

Cite this article as: Nanda SS, Dash S, Huria A, Mehra R. An observational study on extraperitoneal caesarean section in present era. Int J Reprod Contracept Obstet Gynecol 2014;3:724-7. 